\title{
PARCERIA - UMA ESTRATÉGIA PARA PROMOÇÃO DA SAÚDE
}

M ercedes Trentini' ${ }^{1}$, Denise M .Guerreiro V. da Silva², M aria A Ibertina B .Pacheco ${ }^{3}$, M argareth L.M artins ${ }^{4}$

RESUM O: Experiência de parceria do Núcleo de Convivência em Situações Crônicas de Saúde (NUCRON), a A ssociação Catarinenese de Ostomizados (A CO) e do Programa de A ssistência ao O stomizado (PA O). 0 processo de parceria iniciou em 1989, durante o qual foram conduzidos quatro projetos conjuntos, com enfoques na descoberta das potencialidades dos grupos e na expansão da A CO. A idéia de parceria foi criada para envolver os associados da A CO num processo de desenvolvimento de suas potencialidades individuais e coletivas e, com isso, fortalecer e expandir a ACO.

DESCRITORES: Promoção da Saúde.

\section{PARTNESHIP - A STRATEGY FOR HEALTH PROMOTION}

ABSTRACT: The focus is on the partnership experience of the NUCRON (N ucleus ps Studies on chronical conditions.) A CO (Ostomized A ssociation of the State of Santa Catarina) and the PA O (Program of Ostomized Patient Care). The partnership has been in progress since 1989, period in wich four research projects were conduted. The main partnership purpose was to envolve the ostomized patientes in a process os discovering their own potentialities in order to transform the $\mathrm{ACO}$ in a powerful Association.

DESCRIPTORS: Health promotion. 
A parceria aqui apresentada está ocorrendo entre o Núcleo de Convivência em Situações Crônicas de Saúde (NUCRON), a A ssociação Catarinense de Ostomizados (A CO) e o Programa de A ssitência ao Ostomizado (PA O). O NUCRON consiste em um grupo de profissionais da saúde e estudantes de graduação e pós-graduação, com 0 propósito de desenvolver conhecimentos referentes à saúde e, mais especificamente, a saúde de pessoas em condição crônica, mediante atividades de pesquisa, ensino e assistência. A ACO, criada em 1984, conta com aproximadamente 600 associados, que são atendidos pelo Programa deA ssistência ao Ostomizado do SUS/SC em 17 pólos (cidades) do Estado e tem sede na cidade de Florianópolis. A tualmente está se empenhando na organização de núcleos regionais, que coincidem com os pólos do Programa deA ssistência ao Ostomizado do SUS. O PA O (Programa deA ssistência ao Ostomizado) faz parte de um plano deA ssistência global à população desenvolvido numa clínica de referência do SUS em Florianópolis. Especificamente o PAO atende 17 pólos espalhados no Estado, onde são fornecidas bolsas de ostomia.

A aproximação do NUCRON e ACO iniciou em 1989, quando fomos solicitados pela coordenadora do Grupo de A poio ao Ostomizado (GA O) para desenvolver estudos de pesquisa com os associados da A CO. A partir de então, o NU CR ON marcava presença em todas as reuniões da A CO, com o propósito de conhecer a qualidade de vida dos ostomizados, ou seja, suas aspirações, necessidades, problemas, angústias, al egrias, enfim a vida no seu dia-adia. A pós três anos de convívio, durante encontros de duas a três horas mensais, essas entidades apresentavam sinais de afinidade. Os resultados dos trabalhos de pesquisa desenvolvidos pelo NUCRON com os ostomizados contribuíram para um maior entrosamento entre os membros dos grupos. A lguns dos resultados desse convívio mostraram que os ostomizados viviam em constantes preocupações: a quisição de bolsas de ostomia de boa qualidade, o cuidado do ostoma, a al imentação adequada, a sexualidade, e com a opi nião dos outros em relação a eles. Havia quem se percebia inferior a outras pessoas por ser ostomizado, outros se consideravam como deficientes físicos e havia os que já tinham superado essa fase, e se percebiam como pessoas normais (Trentini et al, 1992). A dimensão dessa preocupações e percepções era tal que conduzia a sérios problemas: insônias, gastrites, enterites, dermatites e outras "ites" além do isolamento social, conflitos familiares e tendência suicida.

Com a devolução desses resultados ao grupo da ACO, iniciamos uma reflexão e redefinição de nossas concepções referentes à real idade dos ostomizados, a qual resultou na elaboração e implementação de um plano de ação conjunta. A implementação do plano em parceria foi, de certa forma, facilitado pelo fato de que, a partir de 1992, a coordenação do NU CR ON bem como a direção da ACO passaram a ocupar espaço no mesmo andar de um pequeno e antigo prédio no centro da cidade, chamado Casa Vida \& Saúde, onde atual mente têm sede outros quatro grupos de pesquisa da UFSC. O NUCRON e A CO, com dois grandes desafios a enfrentar: os problemas mais evidentes no grupo de ostomizados: segundo, instrumentalizar a ACO para se expandir por meio da organização de núcleos nos principais municípios de Santa Catarina. 0 primeiro desafio foi enfrentado pelo desenvolvimento de três projetos em conjunto: reivindicação planejada e organizada junto ao Governo de Santa Catarina, para garantir a disponibilidade gratuita de bolsas de ostomia de boa qualidade, que garantissem melhores condições de vida aos ostomizados. Essa luta felizmente foi coroada com sucesso. 0 outro projeto teve o propósito de estabelecer "ponte indivíduogrupo" (Vieira, 1991), ou seja, cuidar do indivíduo ostomizado nas suas peculiaridades e, por outro lado, mostrar as forças que emanam do relacionamento em grupo de ostomizados, nos quais os participantes compartilhavam experiências, se apoiavam mutuamente e, consequentemente, facilitavam sua integração no grupo. 0 terceiro projeto, objetivou a formação de pequenos grupos de convivência com encontros quinzenais. Nesses encontros, profissionais e ostomizados, compartilhavam experiências, criando situações de que surgiam temas de interesse, que, eram ponderados. Quando necessário, 0 grupo estudava alternativas para solucionar problemas (M artins, 1995). U ma das características desse projeto foi a implementação de uma prática educativa no sentido de facilitar condições para que cada um expressasse livremente suas dúvidas, anseios, preocupações, problemas, e aprendesse a enfrentar tais situações.

Por meio desse projeto foi criado espaço propício para 0 ensino e aprendizagem do enfrentamento, em que todos os membros integrantes do grupo participavam espontaneamente. A vivência em grupo permitia a troca constante entre o saber popular e o saber técnico, resultando numa complementação mútua, ensejando 0 desenvolvimento de estratégias de enfrentamento mais efetivas. 0 processo ensino-aprendizagem, conduzido durante a vivência grupal, tencionava romper com posturas tradicionais rígidas, autoritárias e diretivas. Pelo contrário construiu-se outro vínculo de rel ação, em que o enfermeiro era um integrante do grupo como qualquer outro, apenas facilitado e estimulando a reflexão sobre a realidade social do grupo e sobre sua situação de saúde-doença.

0 segundo desafio se referia à instrumentalização da A CO para proceder à sua expansão; foi enfrentado com a operacionalização de dois outros projetos, sendo que um deles objetivou estudar a trajetória da A CO (pacheco et al, 1995), pois tornou-se necessário conhecer a história da associação para melhor compartilhar esforços na sua expansão.

0 outro projeto, que está sendo implementado em 1995 e 1996, objetiva a criação de rede de intercomunição de ostomizados em Santa Catarina; desta vez, além do 
NUCRON e da ACO, a parceria se estendeu ao Programa de A ssistência ao Ostomizado (PA O) do SUS.

A implementação desse projeto foi planejada em duas fases: A primeira objetivou preparar as lideranças dos ostomizados e profissionais dos 17 núcl eos de ostomizados no Estado de Santa Catarina para conduzir o processo de intercomunicação. Para isso o NU CRON, a A CO e o PA O organizaram um seminário no qual participaram os membros do NUCRON, a diretoria da ACO, representante do PA O, o representante de ostomizados e profissionais de cada pólo. O seminário ocorreu em Florianópolis, em período de três dias: foram discutidos temas de interesse do grupo referentes à saúde e à organização da $\mathrm{A} \mathrm{CO}$. N a organização dos temas procurou-se viabilizar uma participação de maneira equivalente, tanto de ostomizados quanto de profissionais, no sentido de que ambos pudessem expressar suas opiniões, colocar suas questões, apresentar al ternativas na busca de soluções e, principalmente, compartil har suas experiências. Dentre as propostas do seminário, al gumas tiveram destaque e foram assumidas como compromisso dos participantes: A criação de um jornal da $\mathrm{ACO}$, com a participação do PAO e NUCRON, formação de grupos de vivências em cada um dos N úcleos, formação e/ou consolidação daA CO em cada um dos $N$ úcleos e realização do cadastramento dos ostomizados de todo o estado.

A tualmente estamos iniciando a segunda etapa do projeto de intercomunicação; para isso os componentes do NUCRON, a diretoria da ACO e representantes dos profissionais de nove pólos, reunidos em Florianópolis, planejaram seminários em quatro pólos estratégicos; Joaçaba, Rio do Sul, J oinville e A raranguá. Esses pólos reunirão os seus ostomizados e profissionais, assim como centros vizinhos com o objetivo de organizar núcleos que possam encadear os núcleos de cada região e a A ssociação e dos próprios núcleos entre si.

A creditamos que essa "frente" em trabal ho de parceria pelos (NUCRON, ACO e PAO) contribui na promoção da Saúde da população ostomizada de Santa Catarina. Os componentes do NUCRON assumiram oS princípios da Promoção da Saúde, definidos na Conferência de Ottawa em 1986, a qual resultou no documento "C arta de Ottawa para a Promoção da Saúde". Esse documento preconiza que a Promoção da Saúde: 1) Vai além da assistência sanitária, requer atuação de qualquer político em qualquer área governamental; 2) atua sobre os determinantes das enfermidades; 3 ) reforça a ação e organização comunitária, utilizando vários enfoques o que incluiu educação e informação, desenvolvimento de habilidades e ações legais de defesa da saúde, e isso implica que os profissionais da saúde devem aprender novas maneiras de trabalho baseadas mais na abordagem em trabal har com elas e para elas mais do que sobre elas; 4) a promoção da saúde depende particularmente da participação da comunidade. (A shton, 1987).

Com base nesses princípios, a parceria, atual mente, objetiva conduzir um processo de instrumentalização da A CO na sua expansão, principalmente por meio da participação, da educação em saúde e informação, a fim de desenvolver nos associados habilidades para enfrentar a defesa da saúde.

Finalmente, apresentamos a seguir um depoimento dos membros da diretoria da $\mathrm{A} C \mathrm{C}$ referente à parceria: foi apresentado numa mesa redonda na II J ornada NorteN ordeste de 0 stomizados em 1985, em Fortal eza.

\begin{abstract}
0 trabalho conjunto com o NUCRON nos favoreceu nos seguintes aspectos: levou-nos a refletir sobre nossa condição de vida, facilitando a compreensão de "estar" ostomizado e também o compartilhar experiências do dia-a-dia em grupo: isso nos levou a aprender e ensinar que não éramos os únicos nesta condição de pessoas ostomizadas. 0 grupo passou também a conhecer seus tal entos e potencial idades e desta maneira a A CO passou a se conduzida e administrada pelos próprios membros da A ssociação, com parceria dos profissionais da saúde, que antes a dirigiam. Outro ponto alto da pesquisa foi que nos trouxe oportunidade de refletir sobre nossa maneira de agir e, assim, poder corrigir os desvios, descobrindo que cada um de nós tem qualidades, forças e potencialidades para viver melhor. A pesquisa nos despertou também a consciência de cidadão, ou seja, aprendemos a lutar em grupo pelos direitos e deveres, portanto a exercer nossa cidadania. 0 trabaIho conjunto contribuiu, por outra, na satisfação de nossas necessidades quanto ao manuseio da bolsa, cuidado com o ostoma, alimentação, problemas diversos como sexualidade, isolamento social e relacionamento em intermédio do relacionamento em grupo "ostomizado com ostomizado" e "ostomizado com não ostomizado".
\end{abstract}

\section{REFERÊNCIAS}

1. A SHTON, J. La promoción de la salud: un nuevo concepto para una nueva sanidad. Valenciana: Talleres Gra'ficos Ripoli, 1987.

2. MARTINS, L.M. Ensinando e aprendendo em grupo a enfrentar situações vivenciadas como ostomizado. Florianópolis, 1995. Dissertação (M estrado) - Departamento de Enfermagem, U niversidade F ederal de Santa Catarina.

3. PACHECO, M.A.B. The group organization process: trajectory of catarinense ostomized patientes association, W CET Journal, v.15, n.3, p.8-14, Jul/Sept, 1995.

4. TRENTINI, M .et al. Vivendo com um ostoma: um estudo preliminar. Revista Gaúcha de Enfermagem, Porto Alegre, v.13, n.2, p.22-28, 1992.

5. VIEIRA, J.C.M. A ponte indivíduo-grupo: uma prática do modelo de adaptação. Florianópolis, 1991. Dissertação (M estrado) - Departamento de Enfermagem, Universidade Federal de Santa Catarina. 